\title{
The Evaluation of Upper Airway Complications Secondary to Intubation: Cuff Pressure Manometer Versus Conventional Palpation Method
}

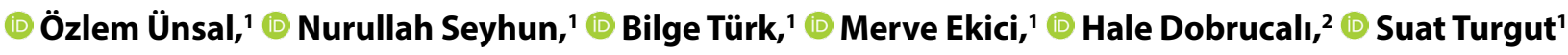 \\ 'Department of Otolaryngological, Şişli Etfal Training and Research Hospital, İstanbul, Turkey \\ 2Department of Anesthesia and Reanimation, Şişli Etfal Training and Research Hospital, İstanbul, Turkey
}

\begin{abstract}
Objectives: General anesthesia is preferred in most otorhinolaryngologic surgeries. The aim of the present study was to evaluate upper airway complications secondary to intubation including sore throat, cough, dysphonia, and dysphagia considering endotracheal tube (ET) cuff pressure, tube diameter, and duration of intubation.

Methods: After the assignment of 67 patients to the study and control groups, ET cuff pressure was adjusted to be between 20 and $30 \mathrm{~cm} \mathrm{H} \mathrm{H}_{2} \mathrm{O}$ using a cuff pressure manometer in the study group. In the control group, the cuff pressure was decided by the anesthesiologist using the conventional palpation method. Sore throat, cough, dysphonia, and dysphagia were compared between the groups at 4,8 , and $24 \mathrm{~h}$ postoperatively.

Results: Cuff pressure was significantly higher in the control group than in the study group. In the control group, sore throat was more frequently observed at 4, 8, and $24 \mathrm{~h}$, whereas in the study group, cough and dysphonia were more often observed at 4 and $8 \mathrm{~h}$. At 4 and $8 \mathrm{~h}$, cough was found to be related to the duration of intubation.

Conclusion: Arrangement of cuff pressure using a cuff manometer is suggested to decrease complications of the upper airway secondary to intubation because of the higher rate of these complaints in patients whose cuff pressure is arranged by the conventional palpation method.

Keywords: Cough; cuff pressure; intubation; sore throat.

Please cite this article as "Ünsal Ö, Seyhun N, Türk B, Ekici M, Dobrucalı H, Turgut S. The Evaluation of Upper Airway Complications Secondary to Intubation: Cuff Pressure Manometer Versus Conventional Palpation Method. Med Bull Sisli Etfal Hosp 2018;52(4):289-295".
\end{abstract}

G eneral anesthesia is widely preferred in otorhinolaryngology surgery. It provides advantages in terms of both patient and physician comfort, but may cause postoperative complaints due to intubation. Intubation of patients after anesthesia induction and inflation of the endotracheal tube (ET) cuff prevent aspiration of liquids, such as intraoral secretions and blood, into the lower airways, leakage of inhalation anesthetics, and also ensure good ventilation of the patient.
However, the pressure applied by the ET cuff to the inner wall of the trachea may cause relatively mild upper respiratory tract complications, such as sore throat, cough, hoarse voice, and cough, and it may lead to the development of more severe complications, such as ischemia, ulceration, necrosis, tracheoesophageal fistula, and even tracheal rupture in patients with prolonged intubation. ${ }^{[1]}$ For shortterm operations not exceeding a few hours, severe postoperative airway complications related to ET cuff pressure

Address for correspondence: Özlem Ünsal, MD. Şişli Etfal Eğitim ve Araştırma Hastanesi, Kulak Burun Boğaz Anabilim Dalı, İstanbul, Turkey Phone: +90 5326919993 E-mail: ozlemunsal@hotmail.com

Submitted Date: December 14, 2017 Accepted Date: December 21, 2017 Available Online Date: December 28, 2018

${ }^{\circ}$ Copyright 2018 by The Medical Bulletin of Sisli Etfal Hospital - Available online at www.sislietfaltip.org

This is an open access article under the CC BY-NC-ND license (http://creativecommons.org/licenses/by-nc/4.0/). 
are not mostly encountered, but complaints, such as sore throat, cough, and hoarseness, may be uncomfortable for postoperative patients, surgeons, nurses, and assistants. Therefore, we aimed to investigate the effects of ET cuff pressure on postoperative airway complications and dysphagia.

\section{Methods}

This was a prospective controlled study. Patients who underwent surgery under general anesthesia with various indications between November and December 2017 in the Otorhinolaryngology and Head \& Neck Surgery Clinic of our hospital were included in the study. There were 39 male and 28 female patients. The study was approved by the ethics committee of Sisli Etfal Research and Training Hospital. Adult patients aged $>18$ years who were hospitalized for surgery to be performed under general anesthesia were evaluated for their eligibility.

Patients scheduled for direct laryngoscopy and biopsy, microlaryngoscopic surgery, tonsillectomy, adenoidectomy, triple biopsy, and surgeries in the oral cavity, such as soft palate and trachea, oropharynx, hypopharynx, larynx, and trachea; with a history of allergy, asthma, reflux, upper respiratory tract viral or fungal infections, and cancer surgeries; who received radiotherapy; and who underwent intubation trials for more than once within the previous year were excluded from the study. Patients scheduled for tympanoplasty and tympanomastoidectomies, stapes surgery, septoplasty, septorhinoplasty, endoscopic sinus surgery, excisional biopsies from the neck, surgical interventions not involving the oropharynx, hypopharynx, larynx, and trachea were included in the study. The patients were informed about the study. Informed consent was obtained from the patients.

The patients were not medicated before surgery. Standard general anesthesia was delivered by the same anesthesiologist. Propofol and rocuronium were preferred for induction of anesthesia. Anesthesia was maintained with sevoflurane and intravenous remifentanil in the oxygen-air mixture. Nitrogen protoxide was not used.

Age, sex, duration of intubation in hours, number of attempts for intubation, extubation time, diameter of the ET, and the type of the operation performed were recorded.

The patients were divided into two groups as the study and control groups. The study group patients were intubated after the ET cuff pressure was adjusted using a hand-type cuff pressure gauge (Tracoe cuff pressure monitor; Tracoe medical $\mathrm{GmbH}$, Nieder-Olm, Germany) to $20-30 \mathrm{~cm} \mathrm{H}_{2} \mathrm{O}$ pressure that was controlled three times until extubation. In the control group patients, after intubation, the pressure of the ET cuff was controlled and adjusted by palpation by the anesthesiologist.

During surgery, cuff pressures were randomly measured three times using the same hand-held cuff pressure gauge (Tracoe cuff pressure monitor). The pressure was not intervened. The mean of three measurements was calculated as the average cuff pressure. At the end of the operation, patients were extubated and awakened in the postoperative care unit. Patients without nausea and vomiting symptoms who recovered their consciousness were transferred to our clinic.

Peroral paracetamol ( $15 \mathrm{mg} / \mathrm{kg} /$ dose every $4 \mathrm{~h}$ ) was started routinely in all patients. Patients were allowed to start oral food intake at $4 \mathrm{~h}$ postoperatively. All patients (study and control group) were evaluated for intubation-related complications at 4, 8, and $24 \mathrm{~h}$ postoperatively. Sore throat was questioned using the Visual Analogue Scale (VAS) scores ranging between 0 and 10 points ( 0 minimum and 10 maximum). Complaints of annoying and tickling cough, muffled or hoarse voice, and difficulty in swallowing of liquid and solid foods were recorded as present/absent, and the findings of all patients were transferred to the computer-based data system.

\section{Statistical Analysis}

Statistical analysis was made using SPSS version 15.0 for Windows. Descriptive statistics were expressed as numbers and percentages for categorical variables. Student's $t$ test was used for comparison of independent two groups of numerical variables with normal distribution. Mann-Whitney $U$ test was used for comparison of numerical variables with non-normal distribution. Chi-square test was used for comparison of the rates in both groups. Monte Carlo simulation was applied when conditions could not be met. A p value of $<0.05$ was accepted as statistically significant.

\section{Results}

This prospective controlled study was conducted between November and December 2017 at the Otorhinolaryngology and Head \& Neck Surgery Clinic of our hospital. A total of 67 (39 male and 28 female) patients aged between 18 and 59 years who were operated under general anesthesia were included in the study. Of the patients, 31 (17 males and 14 females) were included in the control group, and 36 (22 males and 14 females) in the study group. The mean ages were $34.5 \pm 12.9$ years in the control group and $35.7 \pm 10.6$ years in the study group. There was no statistically significant difference between the groups in terms of gender and mean age ( $p>0.05$; Table 1$)$. 
Table 1. Comparisons between the study and control groups for age, gender, duration of intubation, and endotracheal tube cuff pressure

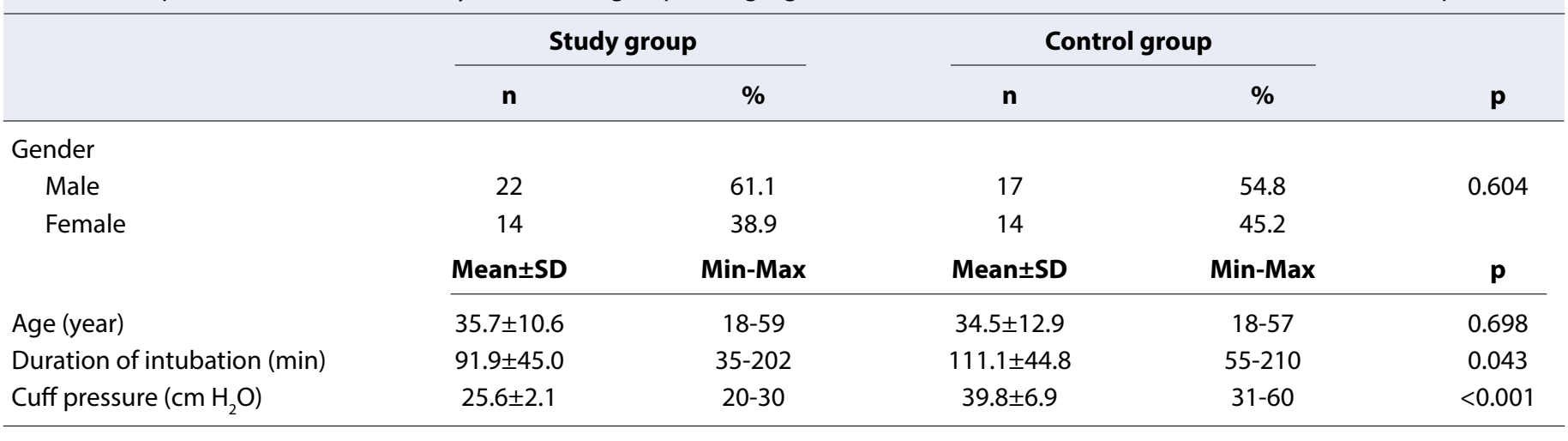

SD: standard deviation; min: minimum; max: maximum

Table 2. Comparison between the study and control groups for diameter of the endotracheal tube $(\mathrm{mm})$

\begin{tabular}{|c|c|c|c|c|c|c|}
\hline & \multirow[b]{2}{*}{$\mathbf{m m}$} & \multicolumn{2}{|c|}{ Study group } & \multicolumn{2}{|c|}{ Control group } & \multirow[b]{2}{*}{$\mathbf{p}$} \\
\hline & & $\mathbf{n}$ & $\%$ & $\mathbf{n}$ & $\%$ & \\
\hline \multirow{4}{*}{$\begin{array}{l}\text { Diameter of the } \\
\text { endotracheal tube }\end{array}$} & 7 & 6 & 16.7 & 9 & 29.0 & 0.074 \\
\hline & 7.5 & 11 & 30.6 & 10 & 32.3 & \\
\hline & 8 & 19 & 52.8 & 9 & 29.0 & \\
\hline & 8.5 & 0 & 0.0 & 3 & 9.7 & \\
\hline
\end{tabular}

The mean duration of intubation was $91.9 \pm 45.0$ and $111.1 \pm 44.8 \mathrm{~min}$, respectively. The duration of intubation was significantly higher in the control group than in the study group ( $p=0.043$; Table 1$)$. When the groups were compared in terms of the cuff pressures of the ET, the mean cuff pressure estimated in the control group was statistically significantly higher than that in the study group $(p<0.001$; Table 1$)$. A statistically significant difference was not detected between the groups as for diameter of the ET ( $>0.05$; Table 2).

The mean VAS scores of the patients in the control group were significantly higher than those in the study group $(p<0.001, p<0.001$, and $p<0.001$, respectively; Table 3$)$.

When the groups were compared in terms of postoperative cough, this complaint was statistically significant in the

Table 3. Intergroup comparisons of the mean VAS scores of sore throat

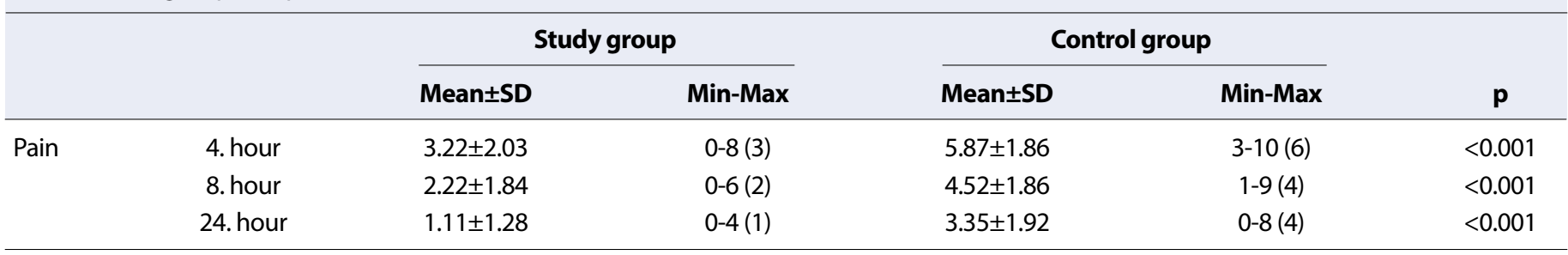

SD: standard deviation; min: minimum; max: maximum

Table 4. Comparison between the study and control groups for cough, dysphagia, and dysphonia

\begin{tabular}{|c|c|c|c|c|c|c|}
\hline & & \multicolumn{2}{|c|}{ Study group } & \multicolumn{2}{|c|}{ Control group } & $\mathbf{p}$ \\
\hline & 8. hour & 3 & 8.3 & 16 & 51.6 & $<0.001$ \\
\hline & 24. hour & 2 & 5.6 & 4 & 12.9 & 0.404 \\
\hline \multirow[t]{2}{*}{ Dysphagia } & 4. hour & 8 & 22.2 & 17 & 54.8 & 0.006 \\
\hline & 24. hour & 2 & 5.6 & 5 & 16.1 & 0.236 \\
\hline \multirow[t]{3}{*}{ Dysphonia } & 4. hour & 7 & 19.4 & 19 & 61.3 & $<0.001$ \\
\hline & 8. hour & 1 & 2.8 & 7 & 22.6 & 0.020 \\
\hline & 24. hour & 1 & 2.8 & 2 & 6.5 & 0.592 \\
\hline
\end{tabular}


Table 5. Evaluation of the correlation between mean sore throat and duration of intubation

\begin{tabular}{lcccc}
\hline & & \multicolumn{2}{c}{$\begin{array}{c}\text { Duration of } \\
\text { intubation }\end{array}$} \\
\cline { 3 - 5 } & & rho & p \\
\hline Study group & Pain & 4. hour & 0.174 & 0.310 \\
& & 8. hour & 0.251 & 0.140 \\
Control group & Pain & 24. hour & 0.126 & 0.465 \\
& & 4. hour & 0.133 & 0.474 \\
& & 8. hour & 0.254 & 0.168 \\
& & 24. hour & 0.099 & 0.596 \\
\hline
\end{tabular}

control group patients at postoperative 4 and $8 \mathrm{~h}$ compared with the study group ( $p<0.001$ and $p<0.001$, respectively). There was no significant difference between the groups as for the complaint of cough at postoperative $24 \mathrm{~h}(\mathrm{p}>0.05$; Table 4). The complaint of dysphagia was significantly more frequently encountered in the control group at postoperative $4 \mathrm{~h}$ than in the study group ( $p=0.001$ ). There was no statistically significant difference in the rates of dysphagia in the groups at postoperative 8 and $24 \mathrm{~h}$ ( $p>0.05$; Table 4). The patients in the control group complained of hoarseness statistically significantly more frequently at postoperative 4 and $8 \mathrm{~h}$ than those in the study group $(\mathrm{p}<0.001$ and $p=0.02$, respectively). No significant difference was found between the groups in terms of hoarseness at postoperative $24 \mathrm{~h}$ ( $p>0.05$; Table 4). There was no statistically significant correlation between the study and control groups as for the mean VAS scores of sore throat and duration of intubation ( $p>0.05$; Table 5).

Table 6. Comparison between mean duration of intubations in patients with and without complaints of cough, dysphagia, and dysphonia

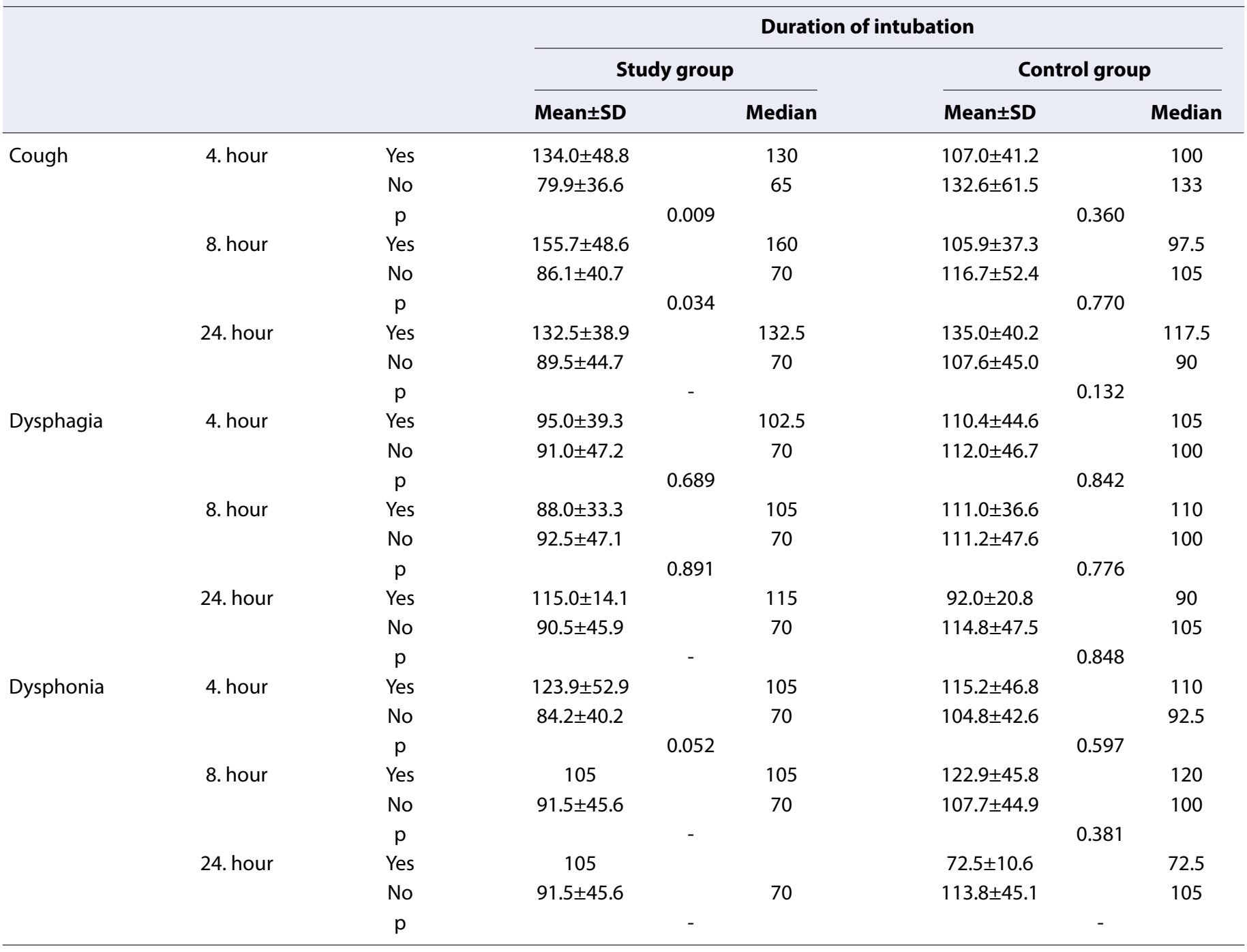


Table 7. Evaluation of the correlation between mean pain scores of sore throat with diameter of the endotracheal tube

\begin{tabular}{lcccc}
\hline & & \multicolumn{2}{c}{$\begin{array}{c}\text { Diameter of the } \\
\text { endotracheal tube }\end{array}$} \\
\cline { 3 - 4 } & & rho & p \\
\hline \multirow{2}{*}{ Study group } & \multirow{2}{*}{ Pain } & 4. hour & 0.110 & 0.522 \\
& & 8. hour & 0.185 & 0.280 \\
Control group & \multirow{2}{*}{ Pain } & 24. hour & 0.163 & 0.341 \\
& & 4. hour & 0.002 & 0.993 \\
& & 8. hour & -0.054 & 0.772 \\
& 24. hour & -0.100 & 0.594 \\
\hline
\end{tabular}

The mean intubation time of patients with postoperative complaints of cough, dysphagia, and hoarseness was compared with patients without these complaints, and in the study group, intubation times in patients with complaints of cough at 4 and $8 \mathrm{~h}$ were found to be significantly higher than those in patients without complaints of cough ( $p=0.009$ and $p=0.034$, respectively; Table 6 ).

There was no statistically significant correlation between mean VAS scores of postoperative sore throat and ET diameter ( $p>0.05$; Table 7).

When the patients were grouped according to ET diameter $(7,7.5,8$, and $8.5 \mathrm{~mm})$ and then compared according to postoperative cough, dysphagia, and hoarseness, any statistically significant difference was not detected between the groups ( $p>0.05$; Table 8 ).

\section{Discussion}

General anesthesia is a type of anesthesia that is frequently preferred in the field of otorhinolaryngology. Although this type of anesthesia is preferred for patient's better compliance with the surgical treatment and the comfort of the physician, the pressure of the ET cuff to the tracheal mucosa may cause serious complications, such as mucosal ischemia, ulceration, necrosis, tracheoesophageal fistula, or tracheal rupture, ${ }^{[1-5]}$ as well as mild but disturbing complications, such as sore throat, cough, and dysphonia. Patients with dysphagia have also been reported although the main complaints are related to the airway. ${ }^{[6]}$ After the insertion of the ET into the larynx, the cuff of the tube is inflated, and the patient's breathing is ensured by mechanical or manual ventilation throughout the operation. Although measurement of the pressure after inflating the ET cuff has been recommended, this practice is not routinely performed in many hospitals. ${ }^{[7]}$ In the literature, it has been suggested to keep the ET cuff pressure in the range of $15-25 \mathrm{mmHg}$ to reduce tracheal morbidity. ${ }^{[8]}$

This pressure range corresponds to approximately 20-33 $\mathrm{cm} \mathrm{H}_{2} \mathrm{O}$ pressure. ET cuff pressure is usually adjusted by

Table 8. Grouping of the patients according to tube diameter and intergroup comparisons for complaints of cough, dysphagia, and dysphonia

\begin{tabular}{|c|c|c|c|c|c|c|c|c|c|c|c|}
\hline & & & \multicolumn{8}{|c|}{ Diameter of the tube (mm) } & \multirow[b]{3}{*}{$\mathbf{p}$} \\
\hline & & & \multicolumn{2}{|c|}{7} & \multicolumn{2}{|c|}{7.5} & \multicolumn{2}{|c|}{8} & \multicolumn{2}{|c|}{8.5} & \\
\hline & & & $\mathbf{n}$ & $\%$ & $\mathbf{n}$ & $\%$ & $\mathbf{n}$ & $\%$ & $\mathbf{n}$ & $\%$ & \\
\hline \multirow[t]{6}{*}{ Cough } & 4. hour & Study & 0 & 0.0 & 3 & 27.3 & 5 & 26.3 & & & 0.562 \\
\hline & & Control & 8 & 88.9 & 7 & 70.0 & 8 & 88.9 & 3 & 100 & 0.685 \\
\hline & 8. hour & Study & 0 & 0.0 & 1 & 9.1 & 2 & 10.5 & & & 1.000 \\
\hline & & Control & 6 & 66.7 & 2 & 20.0 & 6 & 66.7 & 2 & 66.7 & 0.113 \\
\hline & 24. hour & Study & 0 & 0.0 & 1 & 9.1 & 1 & 5.3 & & & 1.000 \\
\hline & & Control & 2 & 22.2 & 1 & 10.0 & 1 & 11.1 & 0 & 0,0 & 0.885 \\
\hline \multirow[t]{6}{*}{ Dysphagia } & 4. hour & Study & 0 & 0.0 & 3 & 27.3 & 5 & 26.3 & & & 0.562 \\
\hline & & Control & 6 & 66.7 & 5 & 50.0 & 3 & 33.3 & 3 & 100 & 0.223 \\
\hline & 8. hour & Study & 1 & 16.7 & 1 & 9.1 & 3 & 15.8 & & & 1.000 \\
\hline & & Control & 1 & 11.1 & 4 & 40.0 & 1 & 11.1 & 1 & 33.3 & 0.389 \\
\hline & 24. hour & Study & 0 & 0.0 & 2 & 18.2 & 0 & 0.0 & & & 0.109 \\
\hline & & Control & 1 & 11.1 & 3 & 30.0 & 1 & 11.1 & 0 & 0.0 & 0.689 \\
\hline \multirow[t]{6}{*}{ Dysphonia } & 4. hour & Study & 2 & 33.3 & 1 & 9.1 & 4 & 21.1 & & & 0.545 \\
\hline & & Control & 7 & 77.8 & 5 & 50.0 & 7 & 77.8 & 0 & 0.0 & 0.068 \\
\hline & 8. hour & Study & 0 & 0.0 & 1 & 9.1 & 0 & 0.0 & & & 0.476 \\
\hline & & Control & 3 & 33.3 & 2 & 20.0 & 2 & 22.2 & 0 & 0.0 & 0.876 \\
\hline & 24. hour & Study & 0 & 0.0 & 1 & 9.1 & 0 & 0.0 & & & 0.476 \\
\hline & & Control & 1 & 11.1 & 0 & 0.0 & 1 & 11.1 & 0 & 0.0 & 0.619 \\
\hline
\end{tabular}


palpating the cuff depending on the personal experience of the anesthesiologist. Sole et al. ${ }^{[8]}$ reported that the palpation method can be adjusted to $15-25 \mathrm{mmHg}$ in only $54 \%$ of the patients (20-33 $\mathrm{cm} \mathrm{H}_{2} \mathrm{O}$ ). According to Svanson et al. ${ }^{[9]}$, cuff pressure was detected to be $>30 \mathrm{mmHg}(40.7 \mathrm{~cm}$ $\mathrm{H}_{2} \mathrm{O}$ ) in $58 \%$ of the patients adjusted with this technique. It has been reported that perfusion decreases, and ischemia occurs in the tracheal mucosa when the cuff pressure increases to $>30 \mathrm{~cm} \mathrm{H}_{2} \mathrm{O}^{[10]}$

In the present study, cuff pressure was kept $<30 \mathrm{~cm} \mathrm{H}_{2} \mathrm{O}$. In addition to cuff pressure in intubation-induced tracheal morbidity, the duration of intubation and the diameter of the ET were also reported to be effective factors. ${ }^{[11,12]}$ For these reasons, we aimed to investigate the effects of ET cuff pressure, ET diameter, and duration of intubation on postoperative airway complications in patients undergoing general anesthesia in our clinic for operations not involving the oropharynx, hypopharynx, and larynx including tympanoplasty, tympanomastoidectomy, stapes surgery, neck mass excision, septoplasty, rhinoplasty, and endoscopic sinus surgery.

The mean cuff pressures were $25.6 \pm 2.1 \mathrm{~cm} \mathrm{H}_{2} \mathrm{O}$ in the study group and $39.8 \pm 6.9 \mathrm{~cm} \mathrm{H}_{2} \mathrm{O}$ in the control group. ET cuff pressure was found to be significantly higher in the control group in which the anesthesia specialist used the palpation technique than in the study group patients for whom manometer was used. Not using the manometer resulted in the overinflation of the cuff. In the literature, a correlation was found between high cuff pressure and sore throat due to tracheal irritation within the first $24 \mathrm{~h}^{\left[{ }^{[1]}\right.}$

Consistent with this, in the present study, the mean VAS scores of sore throat at 4, 8, and $24 \mathrm{~h}$ in the control group patients were statistically significantly higher than those in the study group. However, it has been reported that ET tubes with large diameters are trapped inside the trachea lumen, and the prolonged mucosal contact with the tube can cause sore throat. ${ }^{[13]}$ Although sore throat was more frequently reported in patients intubated with larger ETs ( 9 and $8.5 \mathrm{~mm}$ ) than in those with smaller ETs (7.5 and 7 $\mathrm{mm}){ }_{1}^{[13]}$ there was no correlation between sore throat and ET diameter in the present study. This may be due to the fact that $73.1 \%$ of the patients were intubated with relatively small diameter ETs $(7.5$ and $8 \mathrm{~mm})$. When the duration of intubation was compared with the development of postoperative sore throat, no significant relationship was found in both the study and control group patients.

An irritating, annoying cough due to tracheal irritation and inflammation is another common complaint after intubation. ${ }^{[1]}$ Mechanical irritation and inflammation of the tracheal mucosa trigger cough by activating sensory re- ceptors. ${ }^{[14]}$ Post-extubation cough, hemodynamic changes, arrhythmia, and increases in intraocular and intracranial pressures may cause undesirable results, such as bronchospasm. ${ }^{[15]}$ According to the literature, the rate of cough secondary to intubation varies between $40 \%$ and $96 \% .{ }^{[16]}$

In the present study, annoying cough was observed in $83.9 \%$ and $51.6 \%$ of the control group patients at 4 and $8 \mathrm{~h}$ postoperatively, respectively. No significant difference was found between the groups at $24 \mathrm{~h}$ postoperatively regarding the rates of cough.

A significantly higher frequency of cough seen in the control group may be explained by higher cuff pressure in the control group, whereas the duration of intubation was found to be statistically significantly longer in patients with complaints of cough at postoperative 4 and $8 \mathrm{~h}$ in the study group where ET cuff pressure was kept at low levels than in patients without complaints of cough at these time points. However, no relationship was found between the formation of cough and the diameter of ET. Therefore, while high cuff pressure appears to be effective in the formation of cough, low cuff pressure that is effective for a long time also gives the impression of triggering cough formation.

In the present study, complaints of hoarse or muffled voice similar to complaints of cough were observed significantly more frequently in the control group patients with high cuff pressure at 4 and $8 \mathrm{~h}$ postoperatively. According to the literature, changes in voice after intubation were associated with high ET cuff pressure. ${ }^{[17]}$ However, it is expected that the ET cuff will not cause dysphonia because it is inflated below the vocal cord level during intubation. The main cause of changes in the voice was the mechanical trauma of the tube during endotracheal intubation and edema of the vocal cords due to abrasion. ${ }^{[1]}$

However, excessive inflation of the ET cuff may cause the lower surfaces of the vocal cords to come into contact with the cuff. This may explain the significant alterations in voice in patients intubated with high ET cuff pressures. Recurrent attempts at intubation can also cause mechanical damage to the vocal cords. However, in the present study, patients in whom intubations were attempted more than once were excluded from the study. Any correlation was not found between duration of intubation, ET diameter, and dysphonia at postoperative 4,8 , and $24 \mathrm{~h}$.

Although in the absence of an airway complication, dysphagia is a complaint that can be encountered after intubation. It has been reported that it may be due to mechanical trauma caused by ET or laryngeal retractor. ${ }^{[18]}$ In the present study, the rates of dysphagia were $54.8 \%$ and $22.2 \%$ at $4 \mathrm{~h}$ after extubation in the control and study groups, respectively. This difference was statistically significant. A 
significant difference between both groups could not be detected at postoperative 8 and $24 \mathrm{~h}$ for dysphagia. A significant relationship was not detected between intubation time and ET diameter and dysphagia. Although difficulty in swallowing is higher in the early postoperative period in the control group patients with high cuff pressure, we think that it would be appropriate to increase the sample group and randomization in order to correlate this complaint with the increased cuff pressure.

The most important limitation of our study is that objective methods cannot be used to evaluate the complications after intubation. Complaints of patients could only be evaluated subjectively.

\section{Conclusion}

Although general anesthesia is the frequently preferred type of anesthesia in the surgical treatment of ear, nose, and throat diseases, complaints secondary to intubation are uncomfortable for both the patient and the physician during the postoperative period. In the present study, we think that the adjustment of the cuff pressure by using the manometer is important in decreasing these complications, especially in patients with complaints of sore throat, cough, and dysphonia that are more frequently found in patients whose ET cuff pressure is $>30 \mathrm{~cm} \mathrm{H}_{2} \mathrm{O}$.

\section{Disclosures}

Ethics Committee Approval: The study was approved by the ethics committee of Sisli Etfal Research and Training Hospital.

Peer-review: Externally peer-reviewed.

Conflict of Interest: None declared.

Authorship Contributions: Concept - Ö.Ü., S.T.; Design Ö.Ü.; Supervision - S.T.; Materials - Ö.Ü., N.S., B.T., H.D.; Data collection \&/or processing - Ö.Ü., N.S., B.T., H.D.; Analysis and/or interpretation - Ö.Ü., S.T.; Literature search - Ö.Ü., N.S.; Writing Ö.Ü.; Critical review - S.T.

\section{References}

1. Liu J, Zhang X, Gong W, Li S, Wang F, Fu S, et al. Correlations between controlled endotracheal tube cuff pressure and postprocedural complications: a multicenter study. Anesth Analg 2010;111:1133-7. [CrossRef]

2. Fan CM, Ko PC, Tsai KC, Chiang WC, Chang YC, Chen WJ, et al. Tracheal rupture complicating emergent endotracheal intubation. Am J Emerg Med 2004;22:289-93. [CrossRef]

3. Deslée G, Brichet A, Lebuffe G, Copin MC, Ramon P, Marquette CH. Obstructive fibrinous tracheal pseudomembrane. A potentially fatalcomplication of tracheal intubation. Am J Respir Crit Care Med 2000;162:1169-71. [CrossRef]
4. Harris R, Joseph A. Acute tracheal rupture related to endotracheal intubation: case report. J Emerg Med 2000;18:35-9. [CrossRef]

5. Hofmann HS, Rettig G, Radke J, Neef H, Silber RE. latrogenic ruptures of the tracheobronchial tree. Eur J Cardiothorac Surg. 2002;21:649-52. [CrossRef]

6. Braz JR, Volney A, Navarro LH, Braz LG, Nakamura G. Does sealing endotracheal tube cuff pressure diminish the frequency of postoperative laryngotracheal complaints after nitrous oxide anesthesia? J Clin Anesth 2004;16:320-5. [CrossRef]

7. Curiel García JA, Guerrero-Romero F, Rodríguez-Morán M. Cuff pressure in endotracheal intubation: should it be routinelymeasured? [Article in Spanish]. Gac Med Mex. 2001;137:179-82.

8. Sole ML, Penoyer DA, Su X, Jimenez E, Kalita SJ, Poalillo E, et al. Assessment of endotracheal cuff pressure by continuous monitoring: a pilot study. Am J Crit Care 2009;18:133-43. [CrossRef]

9. Svenson JE, Lindsay MB, O'Connor JE. Endotracheal intracuff pressures in the ED and prehospital setting: is there a problem? Am J Emerg Med 2007;25:53-6. [CrossRef]

10. Nordin U. The trachea and cuff-induced tracheal injury. An experimental study on causative factors and prevention. Acta Otolaryngol Suppl 1977;345:1-71.

11. Loeser EA, Orr DL 2nd, Bennett GM, Stanley TH. Endotracheal tube cuff design and postoperative sore throat. Anesthesiology 1976;45:684-7. [CrossRef]

12. Loeser EA, Machin R, Colley J, Orr D 2nd, Bennett GM, Stanley TH. Postoperative sore throat--importance of endotracheal tubeconformity versus cuff design. Anesthesiology 1978;49:430-2. [CrossRef]

13. Stout DM, Bishop MJ, Dwersteg JF, Cullen BF. Correlation of endotracheal tube size with sore throat and hoarseness following general anesthesia. Anesthesiology 1987;67:419-21. [CrossRef]

14. Mazzone SB. An overview of the sensory receptors regulating cough. Cough 2005;1:2. [CrossRef]

15. Wetzel LE, Ancona AL, Cooper AS, Kortman AJ, Loniewski GB, Lebeck LL. The effectiveness of $4 \%$ intracuff lidocaine in reducing coughing during emergence from general anesthesia in smokers undergoing procedures lasting less than 1.5 hours. AANA J 2008;76:105-8.

16. D'Aragon F, Beaudet N, Gagnon V, Martin R, Sansoucy Y. The effects of lidocaine spray and intracuff alkalinized lidocaine on the occurrence of cough at extubation: a double-blind randomized controlled trial. Can J Anaesth 2013;60:370-6. [CrossRef]

17. Combes $X$, Schauvliege F, Peyrouset O, Motamed C, Kirov K, Dhonneur $G$, et al. Intracuff pressure and tracheal morbidity: influence of filling with saline during nitrous oxide anesthesia. Anesthesiology 2001;95:1120-4. [CrossRef]

18. Arts MP, Rettig TC, de Vries J, Wolfs JF, in't Veld BA. Maintaining endotracheal tube cuff pressure at $20 \mathrm{~mm} \mathrm{Hg}$ to prevent dysphagia after anterior cervical spine surgery; protocolof a double-blind randomised controlled trial. BMC Musculoskelet Disord 2013;14:280. [CrossRef] 